\title{
Emotionally Charged Aesthetic Experience
}

\section{Määttänen, Pentti}

Springer

2015

Määttänen , P 2015 , Emotionally Charged Aesthetic Experience . in A Scarinzi (ed.), Aesthetics and the Embodied Mind : Beyond Art Theory and the Cartesian Mind-Body Dichotomy . Contributions To Phenomenology, vol. 73 , Springer, Dordrecht, pp. 85-99 .

http://hdl.handle.net/10138/232315

acceptedVersion

Downloaded from Helda, University of Helsinki institutional repository.

This is an electronic reprint of the original article.

This reprint may differ from the original in pagination and typographic detail.

Please cite the original version. 


\title{
Emotionally Charged Aesthetic Experience
}

Pentti Määttänen

\begin{abstract}
In traditional aesthetics, the typical characteristic of aesthetic experience is said to be pure disinterested beauty. However, the discussion based on this notion is burdened with the philosophical background assumptions of German idealism. In his Art as Experience John Dewey challenged the classical philosophical tradition and presented the key ideas for developing a new concept of aesthetic experience. In order to understand his pragmatist notion of aesthetic experience it is necessary to discuss a number of topics concerning pragmatist the challenge to classical philosophy. The philosophical naturalism of pragmatism questions the traditional distinction between the changing empirical world and the mind-independent real world as an object of genuine knowledge. There is only one world and we are in it. Dewey's naturalism is, however, in important respects different from the main trend in contemporary naturalism. Further, the pragmatist conception of experience must be clearly distinguished from the traditional notion of experience as sense experience. Action and practice are modes of experiencing and understanding the world. The third topic concerns the naturalistic denial of any immaterial substances. The mind is necessarily embodied, but this is not enough to remove the classical dichotomy between internal and external. A fourth questionable dichotomy in classical philosophy is related to this: the sharp
\end{abstract}


distinction between reason and experience. The pragmatist notion of meaning undermines this dualism. This notion of meaning also serves as a basis for understanding Dewey's comments on the meanings typical in art. Finally, the emotionally expressive power of art requires an explanation. A discussion of all these points helps to clarify the character of the pragmatist notion of aesthetic experience developed below.

\section{Philosophical naturalism}

Generally speaking naturalism maintains that human beings are live creatures. The question stemming from the $1900^{\text {th }}$ century is the following: What has to be changed in philosophy if Charles Darwin is right? One sure thing is that there is no longer room for any absolutely a priori method for attaining eternal timeless truths about the genuine object of knowledge, about the real world as opposed the experienced world. Willard van Orman Quine put it quite clearly by saying that epistemology is just a chapter in empirical psychology. He understands psychology as a branch of natural science, and ended up with reductionism in his philosophy of mind and an emphasis on brain research. Quine's naturalism relies on hard natural scientific methods. 
John Dewey's naturalism can be called soft naturalism as distinguished from Quine's hard naturalism (Määttänen 2006). According to Dewey, culture is a product of nature. He viewed science as problem solving. Naturalism involves no a priori commitment to the methods of natural science. Any method can be used if there is reason to assume that using it may produce information that helps to solve the problem at hand. The point of agreement between hard and soft naturalism is the conviction that classical epistemology is based on outdated metaphysical assumptions.

The way out of these assumptions is the conception that there is only one world, and we are in it. The world is causally closed. This entails that everything in the world proceeds through physical causal processes. There is no room for any immaterial consciousness having an effect on the causal processes. Mind is necessarily embodied. However, as we shall see in section 3, this does not necessarily entail that cognition must be reduced to brain processes. What does follow is that all questions concerning the character of cognition are ultimately empirical questions. This is not to underestimate the need for abstract conceptual analysis, the traditional task of philosophers; but all abstract conceptions must have some connection to experience in order to be relevant for the scientific study of cognition. 


\section{Experience and the object of knowledge in pragmatism}

The traditional view in philosophy is that experience is sense perception. Sense organs function as channels through which the internal mind observes the external world. Visual perception has dominated the discussion since it was discovered that the eye functions like a camera obscura. The retinal image was thought to continue to the brain and to change into a mental image. Other senses were analysed in a similar manner. The object of knowledge in this kind of approach is the external world as the hidden cause of perceptions. The hidden causes as such cannot, of course, be perceived, and therefore the task of the experiencing subject is to find out what we can really know about these hidden causes. They form the mind-independent real world that we must come to know. This task is an issue even in the present day philosophy of science.

According to Charles Peirce the pragmatist conception of experience is broader than that of sense experience (CP 1.336). Action and practice are forms of experiencing and understanding the world. This is a major change in the notion of experience. In pragmatism the world is not experienced in the form of individual objects having certain qualities and mutual relations. The world is experienced as possibilities for action. The object of experience is not the perceived world but the objective conditions of action. These conditions are, of 
course, observed, but they do more: they shape our action (more about this in section 4$)$.

Action as a mode of experience changes the former emphasis on hidden causes of perception to the possible future consequences of action. The static view of what is perceived here and now is changed to a dynamic view about what we will perceive if we, in a situation like this, perform certain acts. Life involves orienting to the future on the ground of past experience. The classical conception of two worlds, the empirical world and the real world as a hidden cause of perceptions, is changed into the view that there is only one world but there is still a problematic relation between what is perceived and what is hidden. The hidden world just is not hidden in principle. The future is hidden now, but on the basis of past experience we are able to control the kinds of experiences we will encounter in the future if we perform certain acts.

In pragmatism the object of knowledge is thus defined in a different way. The classical epistemic relation between perceptions and their hidden causes is replaced by a relation between two situations: the one we are in at a certain moment and the other that is a consequence of our activities. As Dewey put it, the guided processes of change form the objects of knowledge (Dewey 1958, 160).

Anticipation of the future is based on experience, which is a complex thing. Evolution has given us a history experience of 
interacting with our environment. This interaction has shaped us as biological organisms. The ultimate reason for our having these organs is the fact that they have made it possible to stay alive on earth. It is also reasonable to believe that some of our inborn capacities, for example the capacity to learn natural languages, are at least partly an outcome of the evolutionary pressures created by the social and cultural environment of our ancestors. According to Merlin Donald, symbols are a product of thought, not vice versa (Donald 2001, 276), and these cognitive capacities must have developed independently of the ability to use language. Conscious human thought has its origin in the complex social organization of primates. To this we have to add the experience accumulated during historical and cultural development. Each new individual faces the task of adopting the skills made possible by this multilevel and ultimately long evolutionary experience. It is obvious that the number of possible learning histories is enormous.

The possibilities for action that open up in the future form a no less complicated scenario. There are always several options for action and their different combinations. And the number of possibilities depends on the number of skills one has adopted on the basis of our shared experiential background. The growing complexity of the social and cultural environment increases the number of possible actions. An adequate analysis of this complex situation requires a dynamic approach where the emphasis is not on what we observe here and now but on what to do on the basis of past experience in an 
observed situation. This pragmatist definition of the object of knowledge also has consequences concerning the relation between facts and values (section 6.1).

\section{Embodied mind}

Naturalism entails that mind is necessarily embodied. The brain is the organ of thought, which is probably why the mind is sometimes identified with the brain. Naturalism does not, however, necessarily imply this identification. Nature is causally closed, but there are other physical causal processes besides the brain processes that may be involved in thinking. The brain is the organ of thought but it is not the brain that thinks. A human being thinks with the brain. Just as the legs are the organs of running but it is not the legs that run. A human being runs with the legs. The brain in a vat will think exactly as well as a pair of legs cut off from a body will run. The conception that mind can be identified with or reduced to the brain is a peculiar form of neo-Cartesianism. What René Descartes said about the soul, is said about the brain (Bennett and Hacker 2003, 103-107). The doctrine of two substances, the material and the mental, is rejected, but the internal/external dichotomy remains. And the so-called hard problem of consciousness also remains: how and why we have subjective phenomenal experiences and what their relation is to brain processes? This problem has its roots in the external/internal 
dichotomy that, however, is not the only way to approach the problem of cognition.

An obvious but not so thoroughly investigated possibility is that the ability to think is not attributed to the brain and not even to the body as a whole but to the system of interaction between an organism and its natural and social environment. John Dewey criticized in 1896 the reflex arc concept and suggested that a concept of a sensorimotor circuit might do better (Dewey 1975a). The difference between an arc and a circuit is precisely in the role of the environment. The objects of environment belong to "the functional organization of mind" (Määttänen 1993, 105). In this approach, mind is constituted by the interaction of an organism and its environment. This changes the hard problem of consciousness. Phenomenal qualities are real relations between biological organisms and their physical environment. They are qualities of concrete interaction. The subjective aspect of experience is based on the fact that mind is embodied and that the body determines one's viewpoint.

Interaction consists of action and perception. They are not so easily distinguished. Peirce writes that in perception the world's effect on us is greater that our effect on it, while in action it is the other way round (CP 1.324). In this way, action and perception form a circuit or a loop where all proceeds through physical causal processes. The basic principle of naturalism, the principle of causal closure, remains in force. This loop of perception and action is a unit of analysis 
within which it makes sense to speak about experiencing the world as possibilities of action on the basis of the experience of past interactions. Present experience extends behind the immediately perceived because past experience enables one to anticipate the consequences of possible courses of action. This unit of analysis is also the framework for defining the pragmatist notion of meaning that explains how the world is experienced as a meaningful environment.

\section{The notion of meaning in pragmatism}

The minimum requirement of something having meaning is cognitive distance. Meanings enable one to think about something that is not immediately present. Language is a system of symbols and a powerful vehicle for thought. However, the pragmatist notion of meaning is wider. It covers both linguistic meanings and tacit (non-linguistic) meanings.

\subsection{Habit of action as meaning}

According to Peirce, what a thing means is simply what habits it involves (CP 5.400). What are habits of action? A habit is formed when a similar action is repeated in similar circumstances. The outcome of this repetition is a structure or scheme of action that has 
the tendency to be reproduced in the future. Habits of action thus enable one to anticipate that habitual action in similar circumstances tends to produce similar experiences as in the past. All that is required is a memory trace about the course of events during the past activities. This takes place by virtue of a habit formation mechanism that I have called the pragmatist law of association (Määttänen 2007). The classical laws of association (similarity, proximity in time or place and causality) are not enough. The basis of association is the fact that in habit formation action must be accommodated to objective conditions of action. Classical laws of association concern internal units, and the associations are supposed to be created literally in the mind (or the brain). But the pragmatist law of association concerns the association of individual acts into a habitual series of acts. Associations are formed during and because of overt activity. These associative chains make anticipation possible. The anticipation of probable future events on the basis of what is observed and what possibilities of action the situation provides is, in effect, to have cognitive distance. One is able to think about something that is not here and now but somewhere else at another time. In other words, one is able to think about the future consequences of action. Habits thus fulfill the minimum requirement of being meaningful.

What are tacit (non-linguistic) meanings? Any object of perception may involve habits. This makes it a sign-vehicle that carries meanings. Most of us have the habit of using the door and not the 
window when exiting a room. Doors and windows have thus different meaning for us. A door refers to certain experiences that we have had and probably will have when using doors. And our evolutionary experience warns us strongly against using a window for exiting a room. Chairs, tables, hammers, buildings and so on have different meanings. As we shall see in section 5, the same also holds for individual qualities. The world experienced as possibilities of action is a world full of meanings that make it possible to think about the consequences of different habitual activities and their combinations. Note that there is no mention of language. The Peircean definition of meaning can be applied to animal cognition and as an account of tacit (non-verbal) meanings as a basis for linguistic meaning.

Meanings are also supposed to be general. For Peirce habits are general, but in what sense? Habits exist as repeated similar activity in similar circumstances, as modes or forms of practices. Peirce approached the problem of generality by asking when does generality arise. In the past there can be only a certain number of acts, and no genuine generality can be involved. Therefore the socalled real generals (or universals) cannot exist in the past. The same holds for the present because only one act can be performed at one time. The only possibility left is the future. Peirce writes that a general fact cannot be fully realized. It is potential and its "mode of being is esse in futuro" (CP 2.148). Peirce says the same thing about meanings (CP 5.427). This implies that general things like meanings 
can only be objects of thought. One can only think of repeating instances of a habit indefinitely many times in indefinite future. But this does not imply any theory of two different substances, mental and material, because all acts are performed in nature, in the material world. Generality exists as repeatable habitual behaviour, generality is continuous activity as Kant put it (stetige Handlund, Kant 1926, 615). Habits as meanings are thus general entities and also in this sense capable of being vehicles of cognition.

What is it to think with habits? Peirce compares it with listening to a melody or a musical phrase. One certainly hears only one note at a time but the listening experience is different. On the basis of what is already heard, one anticipates how the phrase might continue. The phrase is an object of perception or of thought as a whole even though the actual listening or thinking is a temporal process. This is analogous with thinking about habitual action. Accordingly, thought "is a thread of melody running through the succession of our sensations" (CP 5. 395). We think of habitual behavior by anticipating the future course of action on the basis of past experience and by observing changes in environmental conditions. The pragmatist law of association provides the mechanisms for this.

\subsection{Language and meaning}


A traditional way of putting the question of linguistic meaning is to ask by virtue of what does a sequence of letters, 'table', refer to all the tables in the world. This way of putting the question temps one to think that the word has a specific capacity, called intentionality, for referring to something else. Franz Brentano used this concept in psychology and defined mental states as intentional entities having that capacity. Brentano used the analogy between words and mental states. This analogy temps one to think that ideas (thoughts, mental representations) are individual units in the mind.

As George Lakoff and Mark Johnson (1999) write, this Cartesian idea is based on a container metaphor. The familiarity of the metaphor makes the idea easy to understand and easy to adopt. Unfortunately it is also based on the outdated metaphysics of two different substances and keeps the external/internal dichotomy in force. Further, in pragmatist analysis meanings and thoughts are relations. Experience consists of a complex system of relations that are realized in the interaction between an organism and its natural and cultural environment. Relations don't have well defined locations and it would be a logical category error to reduce a relation to one of its elements.

From a pragmatist point of view this way of putting the question is misleading. A better way to approach the problem of linguistic meaning is to point out that we have two types of activities. We do something with linguistic expression and then we have other kinds 
of practical activities. A better question is to ask about the relationship between these activities. This is how John Dewey put it. The word 'hat' gains meaning in the same way as a hat, namely by being used in a certain way (Dewey 1916,18). There is a clear analogy between the use of language and the use of other things, hats, tools and so on. Ludwig Wittgenstein, who famously applied the principle that meaning is use, also refers to this analogy (Wittgenstein 1975, 21). Peircean pragmatism goes further. The relationship between the use of language and the use of tools is more than an analogy. The use of tools and other objects of perception creates meaning structures independently of language. Accurately speaking Wittgenstein's principle is an application of Peirce's wider definition: what a thing means is simply what habits it involves. The use of a linguistic expression surely belongs to the habits involved. Habits of use form a subcategory of all the habits involved.

There are two systems of meanings functioning according to the same principle: meanings are habits of action. One is the system of linguistic meanings and the other is the system of tacit (nonlinguistic) meanings. Language as a system of groups and strings of letters gains its meanings when it is used in the context of other practices that are meaningful in their own right. Consistent naturalism requires a bottom-up strategy. Tacit meanings are primary and basic. Merlin Donald is right in maintaining that symbols are the product of thought. What is the origin of thought? The pragmatist answer is: it is in the development of tacit meanings, 
habits of action as ways of surviving in nature. Another point concerning the priority of tacit meanings is conventionality. Meanings of words are conventional in the sense that the physical properties of words are needed only for the purpose of noticing differences between words. They do not restrict the possible meanings. In tacit meanings things are different. The physical properties of the sign-vehicles, tools, tales, houses and so on and the properties of the agents, human beings as biological organisms, do restrict the possible habits involved and, therefore, the possible meanings. Tacit meanings are not conventional in the same way as linguistic meanings.

\section{Tacit meanings typical for art}

In Art as Experience John Dewey distinguishes between linguistic meanings typical for scientific texts and meanings typical for art (Dewey 1980, 82-105). He discusses mainly painting (poetry and literature are not considered). Science states meanings but art expresses meanings. One distinguishing feature is that meanings do not belong to the word intrinsically. Language is conventional and meanings are something external to the letters of words. In paintings the meanings are present in the picture; the meanings are incorporated or embodied in the canvas. Another distinguishing feature is that meanings in art are individualized. One change in the color, line, form and so on changes the meaning of the picture as a 
whole. Linguistic meanings are what they are independently of the font, color of letters and so on. Linguistic meanings are abstract in a different sense than the meanings that are typical for art. This has to do with the concrete presence of meaning in art. A third important difference is that meanings in art are often emotionally powerful (this aspect is discussed in section 6).

Dewey describes these differences in a few pages but does not give a definite theory of meaning that would explain them. There are only a couple of characterizations of meaning in his book, but one of them is quite informative. "The action and its consequence must be joined in perception. This relationship is what gives meaning; to grasp it is the objective of all intelligence" (Dewey 1980, 44). This is, in effect, the same definition of meaning that Peirce gives: what a thing means is simply what habits it involves. The pragmatist notion of tacit (non-linguistic) meanings outlined above explains these features. Dewey's characterization of meanings is also in accordance with the pragmatist definition of the object of knowledge.

Tacit meanings are always present in any observed situation. Concrete objects of perception, such as chairs, windows, cows, trees and others, are sign-vehicles, carriers of meaning. And the meaning, the consequence of habitual action, belongs to the object of experience (and knowledge). Tacit meanings are interwoven with our concrete life practices. Linguistic meanings form a different and a more abstract layer in the system of meanings. Tacit meanings are 
embodied in the concrete things we encounter when acting in the world. Paintings with their tacit meanings are closer to everyday experience than abstract linguistic meanings. In this sense the tacit meanings are embodied or incorporated in the picture.

Tacit meanings are also individualized every time they are realized. A habit of action gives only a scheme or structure for conduct. The course of habitual action always depends heavily on the actual situation. The actual courses of conduct may vary a lot even though they are instances of the same habit. Tacit meanings also depend on the context in the sense that there are typically a large number of possibilities of action available in any situation. Even if these possibilities are not realized (they all simply cannot be) or consciously considered they add their part to the overall meaning of the situation. The scene of such situated activity is full of meanings. A situation is semantically dense. The same density of meanings applies to paintings. In this way, the meaning of a work of art as a whole is individualized.

The claim that art expresses meanings is open to misinterpretations. Some aesthetic theories maintain that an artist expresses her inner mental life through an external object of art. This is something that Dewey would put into the category of "antiquated psychologies". Meanings are ideas in the mind. Communication is transferring ideas into other minds using language. Since works of art like musical works are not related to conscious ideas in the same way as words, 
the meanings in art and their communicativeness remain a mystery (Määttänen 2003). This view retains the internal/external dichotomy of classical philosophy. In Dewey's aesthetics it is the meanings that are expressive as compared to those of a scientific text. This is not to deny the artists' role in creating expressive works of art. The point is that the word "expresses" is used in a different sense and that the philosophical framework is different.

The way out of the background assumptions of classical philosophy is indicated by Dewey's distinction between the object of art and the work of art. This distinction is also vulnerable to misinterpretations because a work of art is usually considered to be a physical object, for example, a canvas hanging on a wall. In Dewey's terminology a work of art is an experience, and experiences cannot hang anywhere. An object of art may hang on a wall, but the work of art is that object as experienced. And the work of art as an experience is not something private and internal mental state. Dewey consistently criticized this kind of mentalist psychology. Experience is interaction with the environment, and some experiences can be classified as aesthetic (see section 7). The point is that experience (as well as the mind) is a relation (or a system of relations) between a living organism and its environment. A work of art is realized in ongoing experience.

Consider colors. They are experienced as properties of physical objects, but actually they are properties of interaction in the sense 
that they also depend on internal conditions (internal to the body, that is). Light and a reflecting surface are not enough. There has to be a certain kind of biological organism with eyes and other neural structures. These three conditions make it seem that, in actual interaction, colors are experienced as external to the body. There is no need to speculate about colors residing literally in the head as phenomenal qualities. In a similar way emotions are experienced as internal (to the body), but as we shall see in section 6 , in pragmatism they are analyzed as qualities of action. A work of art consists of (actually or potentially) experienced qualities and, as such, it is a relation between an organism and the object of art that is a cause (but not the only cause) of the experienced qualities. Art itself is "a quality of activity" (Dewey 1980, 224).

An object of art is experienced as being expressive. Expressiveness is related to the character of tacit meanings typical for works of art. A work of art is an object of art as understood and interpreted with various kinds of meanings. This holds also for individual qualities. One cannot experience "pure" or "simple" qualities (Dewey 1980, 121). A color as seen is qualified by "implicit reactions of many organs" (ibid., 122). Colors are charged with hidden consequences. In other words, even simple qualities are experienced as belonging to the whole that consists of the present situation, possibilities for action and the anticipated outcomes of habitual activity. This gives the qualities meaning precisely in the sense of the pragmatist notion of meaning defined above. 
The origin of tacit meanings is ultimately from our evolutionary experience. This entails that these meaning structures function largely subconsciously. It is unthinkable that we could remember what kinds of experiences led to the development of our sense organs, for example. However, these experiences have left their trace in the structure and mechanisms of our biological bodies and therefore effect how we experience, understand and interpret our environment.

Meanings, by definition, can be used in thinking and communication. The fact that the tacit meanings of art function largely subconsciously does not prevent this. That subconscious cognitive processes exist is simply an empirical fact. Without any closer analysis there is a temptation to be content with concepts like intuition, creativity and the like. The pragmatist notion of tacit meanings is one attempt to describe the mechanisms of subconscious cognition.

Communication with subconscious tacit meanings is perfectly possible and, ultimately, it is not so different in comparison with writing a text. Recall the distinction between an object of art and a work of art as an experience. An artist works with the object of art using her own experience of it as a standard. She is finished when she is satisfied with her own experience. The object of art is then removed to a gallery, for example. Note that a work of art is not an 
entity that can be removed. Other people come to experience that object of art. Their experiences are similar to the extent they have common background. The tacit meanings of art are effective in communication precisely because their ultimate origin is our evolutionary experience. Historically and culturally established meanings have, of course, their role in experiencing art, and their effectiveness in communication is also based on a shared human background.

Writing a text is not so different. An author produces a text, rewrites it until the long rows and groups of letters state the meanings the author wants to convey. The reader has nothing but the letters plus her own background of reading and writing. Communication is successful to the extent that the author and the reader share a common background of meanings. But meanings, thought contents and experiences are not entities that can be removed from one place to another. They are created anew at each moment. A skilful artist and a skilful writer are able to control the experiences of other people in the direction (or directions) they want.

\section{Values and emotions}


Antonio Damasio (1995) has put forth a hypothesis that he calls the somatic marker hypothesis. According to it emotions are signs of values. It proves to be useful in explaining why an aesthetic experience (in Dewey's sense) is emotionally charged. Damasio's views fit well with the pragmatist notion of meaning.

\subsection{Facts and values in pragmatism}

One of the misleading dichotomies in the classical philosophy is the dualism between facts and values. David Hume, in considering a murder, concluded that there are only certain passions, motives, volitions and thoughts but no other facts that could be called vice (Hume 1978, 468). On the next page he presents the famous principle: no ought from is. These places in Hume's book are quoted quite often.

Between these passages Hume writes that vice and virtue are like sounds, colors, heat and cold in that they "are not qualities in objects, but perceptions in the mind" (Hume 1978, 469). This sentence is not so often quoted. It is, however, important because it reveals the metaphysical framework of Hume's thought. This kind of dichotomy of external and internal is not tenable in consistent naturalism. Heat as molecular movement, as the current definition says, is obviously a property of sun, for example. And, as Hilary Putnam points out, Hume advocates a kind of pictorial semantics 
(Putnam 2004, 15). If something cannot be literally perceived here and now, it cannot belong to the world of facts. Hume's concept of experience admits only perceptions of particular sense qualities.

In pragmatism the notion of experience is different, as is the notion of fact. In pragmatism the world is not experienced as sense qualities. The world is experienced as possibilities for action that lead to anticipated consequences. Accordingly, facts consist of the relation between what is observed here and now and what will be observed later as a consequence of certain kind of conduct. Ongoing activity is the essential feature of experience. Action is possible only on a timeline where outcomes of action can be anticipated (not necessarily consciously) on the basis of past experience.

This viewpoint changes the relation between facts and values. The world is full of possibilities for action, and only one or two activities are usually possible at one time. This entails the need to choose between various courses of conduct. And choice is, in effect, valuation. Some anticipated outcomes are valued more than the others. These values and the choices based on them are, of course, at different levels. Analogously with the system of meanings, value theory also requires a bottom-up analysis. This is the exact contrary to the classical tradition which maintains that values come ultimately from theology or pure conceptual analysis, moral Mount Sinai, or out of the a priori blue, as Dewey put it. 
Naturalism puts human beings in nature where biological organisms are born, live their lives and die. Live creatures have the interesting feature that they tend to live their life until it eventually ends. In fact, there is no choice about that. Another easily observable fact is that live creatures usually strive to survive. And in order to survive one must breath, have water and food, shelter, and so on. This striving creates a natural source of norms that I have called biotechnical normativity (Määttänen 2012). In order to continue one's life one has to make certain choices. These choices are based on the valuation of the expected outcomes of action. A hungry animal values food because she expects to experience something positive after eating it. Experienced satisfaction of hunger is a positive value for all animals and it is, pace Hume, an observable fact in nature. Human beings with history and culture also have other normative structures. In a bottom-up analysis, they are constructed on the basis of the biotechnical normativity that provides an objective basis also for other values.

The outcome of the analysis above is that facts and values are not separable into different realms of being. For an acting agent, facts and values are intertwined. An acting agent is necessarily a valuing agent.

\subsection{Meaningful emotions}


Emotions are experienced as internal states. As such, they are sometimes regarded as causes of action. In William James's example a man is running away from a bear. According to James the actual cause of running is the bear, not the fear. The fear qualifies the running; it is a quality of action. Emotions have an object even if it is not consciously recognized. In other words, emotions are meaningful. The pragmatist notion of meaning explains this. Any object of perception may involve habits. These habits offer anticipations of the possible consequences of dealing with that object of perception. These consequences simply are the meaning of the object.

In Damasio's view, emotions are meaningful signs (somatic markers) of values (Damasio 1995). He maintains that emotions are necessary aids of rational cognition. Alternative courses of action cannot usually be calculated so well that rational choice could be based solely on them. Time and cognitive resources are limited. Damasio describes extreme cases where persons tend to make calculations that are too extensive. According to him these persons have Kantian minds that resemble patients with damages in the frontal lobe. Emotions help us make choices by indicating that it is time to stop calculations. Negative emotions advice immediate avoidance and positive emotions indicate the need to concentrate on how the object of emotion might be accessed. For Damasio emotions are heuristic aids of rational thought. 
The pragmatist notion of meaning contains the idea that habits are tacit meanings and, as such, they are vehicles of rational thought. As pointed out above, the background of tacit meanings is our long evolutionary experience. Objects and features of the environment, with which we associate habits sometimes consciously but most often subconsciously, thus have meanings on the basis of all the experiences encountered as outcomes of these habitual activities. It is evident that we cannot consciously analyze and recollect the evolutionary history of these experiences. However, they have left their trace in the mechanisms of subconscious cognition with tacit meanings and emotions involved here. But the experiences have left a memory trace as their summary. And this also holds for single sense qualities. We cannot experience "pure" or "simple" qualities. They are charged with hidden consequences and, therefore, also with an emotional flavor based on subconscious valuation. It is not accidental that red is experienced differently than blue or green. This is obviously related to the different role of these colors in our evolutionary history.

Dewey discussed this emotional charge and, for some reason, used in this context the German world Gefühlston, a tone of feeling (Dewey 1975b, 188). Single experienced qualities also have this Gefühlston that carries with it memories of past experiences. Emotions are signs of values. The pragmatist notion of meaning is an explicit account of how this sign-relation actually functions. Habitual ways of having experiences help to anticipate what sort of 
experiences can be expected given the presence of certain qualities, objects and combinations of them. Positively valued experiences promote positive emotions and negatively valued outcomes promote negative emotions. Habits as tacit meanings are vehicles of cognition and the outcome of these subconscious cognitive processes become conscious as emotions, as a Gefühlston.

\section{Aesthetic experience in pragmatism.}

The basic aim of pragmatist aesthetics is to recover the connection between art and life. Crudely speaking, the concept and the practices of fine art (or polite arts for the polite classes, as was also suggested) were created in the $1800^{\text {th }}$ century when the bourgeoisie removed paintings and statues to museums and galleries and developed a corresponding aesthetic theory with its principal concept of pure disinterested beauty (Mortensen 1997, Shiner 2001). The notion of pure disinterested beauty is not utterly wrong. It expresses something that is true about experiencing art. Enjoyment offered by art does not have direct relation to the interests of everyday practices. It is often emotionally powerful without any clear connection to specific things that might be causing these emotions. However, all this can be explained without appealing to the philosophical background assumptions of classical philosophy. 
John Dewey emphasized the continuity between everyday experiences and art. Recall that Dewey defined a work of art as an experience produced by an object of art. Dewey's notion of aesthetic experience is not introduced as a tool for sharp categorization of fine art as something separate from other experiences. Art has no privilege concerning aesthetic experiences. Objects and things outside the artworld are also capable of being experienced aesthetically. Dewey uses also the concept of an experience with the emphasis on the article. The purpose of this emphasis is to point out that the experience is in some sense exceptional, worthy to remember, but maybe not quite an aesthetic experience. It is an experience with some aesthetic quality. This continuum of concepts expresses the continuum between fine art and everyday life.

The central feature of an aesthetic experience in Dewey's sense is its consummatory character. It is in some sense finished and complete. It is valuable in itself, not as a means for other experiences. Its value is positive, but this is not tied to any specific concept like beauty or the sublime. The definition is in this sense formal. The content of the experience may vary. It may be beautiful or ugly, pleasurable or fearful. The point is that it is pursued for its own sake. Stendhal suggested that beauty is a promise of happiness. At a more general level we can say that an aesthetic experience is a promise of consummation, and this promise is enjoyable in itself. 
The fact that an aesthetic experience is only a promise of actual consummation entails that it is not directly connected to action. It is not merely a means for other experiences. There is a difference between musical experiences and ticket buying experiences sometimes necessary for getting into a concert. Ticket buying is a clear means for a musical experience that is valuable as such. It is a perceptual experience, only a promise of real consummation to which action might lead. This can be called relative disinterestedness. It is only relative because the connection to action and practice is not completely broken. Basically this follows from the processes of understanding and interpreting. All experiences are understood and interpreted as meaningful in some way or degree, and in pragmatism these meanings are ultimately habitual activities. The vehicles of understanding are practical and therefore connected with the goals and interests of life in general. Disinterestedness is relative also in the sense that aesthetic experiences may be means for cultivation of personality, they often have a social function, and so on.

The emotional power of an aesthetic experience is also explained by the connection with habits as meanings. Emotions are signs of values, but the Gefühlston of perceived qualities of the works of art is based on the long forgotten experience of our evolutionary history. No conscious meanings can necessarily be attached to qualities, but this is a consequence of the subconscious character of the tacit meaning structures that are typical for works of art. What 
can be consciously manipulated is the emotionally charged aesthetic experience, and that is what composers and performers do using their own experience as a model. That is how one communicates: using tacit meanings that have subconscious referents.

Subconscious meanings do refer to past experiences that have shaped our sense organs, cognitive and emotional mechanisms. And the overall subconscious valuation of the referents of these meanings becomes conscious as emotions. Therefore music, for example, is meaningful just because of this (tacit) reference, contrary to what Mark Johnson writes (Johnson 2007, 242-243). According to Johnson music is meaningful but does not refer. That is true if the meanings are supposed to be conscious. However, Peirce's explicit definition of meanings as habits of action gives a basis for suggesting a system of tacit and largely subconscious meanings that do refer. As Dewey pointed out, even single perceptual qualities are charged with hidden consequences that constitute the meaning and the related Gefuihlston of these qualities.

Aristotle distinguished between praxis and poiesis by saying that the goal, telos, of poiesis is something external to the activity while the goal of praxis is the activity itself (Aristotle 1999, 1140b 5-10). The paradigmatic example of praxis is eudaimonia, the good life. Aesthetic experiences are something that are pursued for their own sake, and therefore they are also suitable elements of Aristotelian praxis, good and happy life. 
Aristotle. 1999. Nicomachean Ethics, transl. Terence Irwin. Indianapolis: Hackett.

Bennett, Max \& Hacker, Peter. 2003. Philosophical Foundations of Neuroscience. Oxford: Blackwell.

Damasio, Antonio. 1995. Descartes' Error. New York: Picador.

Dewey, John. 1916. Democracy and Education. New York: The Macmillan Company.

Dewey, John. 1958. Experience and Nature. New York: Dover.

Dewey, John. 1975a. The Reflex Arc Concept in Psychology. In The Early Works 5, 96109. Carbondale: Southern Illinois University Press.

Dewey, John. 1975b. The Theory of Emotion. In The Early Works 4, 152-188. Carbondale: Southern Illinois University Press.

Dewey, John. 1980. Art as Experience. New York: Perigee.

Donald, Merlin. 2001. A Mind So Rare. New York: W.W. Norton \& Company.

Hume, David. 1978. A Treatise of Human Nature, ed. L.A. Selby-Bigge. Oxford: Oxford University Press.

Johnson, Mark. 2007. The Meaning of the Body. Aesthetics of Human Understanding. Chicago: The University of Chicago Press.

Kant, Immanuel. 1926. Reflexionen zur Metaphysik. Kant's gesammelte Schriften 17. Berlin \& Leipzig: Preussische Akademie der Wissenschaften.

Lakoff, Georg \& Johnson, Mark. 1999. Philosophy in the Flesh. New York: Basic Books.

Mortensen, Preben. 1997. Art in the Social Order. The Making of the Modern Conception of Art. Albany: SUNY Press.

Määttänen, Pentti. 1993. Action and Experience. A Naturalistic Approach to Cognition. Annales Academiae Scientiarum Fennicae, B 64, Helsinki.

Määttänen, Pentti. 2003. Riemer on Musical Meaning. Action, Criticism and Theory of Music Education 2 (1).

Määttänen, Pentti. 2006. Naturalism: Hard and Soft. In Science - A Challenge to Philosophy? Ed. Heikki J. Koskinen, Sami Pihlström \& Risto Vilkko, 227-236. Frankfurt am Main: Peter Lang.

Määttänen, Pentti. 2010. Habits as Vehicles of Cognition. In Ideas in Action: Proceedings of the Applying Peirce Conference, ed. Mats Bergman, Sami Paavola, Ahti-Veikko Pietarinen \& Henrik Rydenfelt. Nordic Studies in Pragmatism 1. http://www.nordprag.org/nsp/1/. Accessed 15 September 2012.

Määttänen, Pentti. 2012. Taide maailmassa. Pragmatistisen estetiikan lähtökohtia (Art in the World. An Outline of Pragmatist Aesthetics). Helsinki: Gaudeamus.

Peirce, Charles. 1931-1958. The Collected Papers of Charles Sanders Peirce, ed. Charles Hartshorne, Paul Weiss \& Arthur W. Burks. Cambridge: Harvard University Press (reference is designated $\mathrm{CP}$ followed by volume and paragraph number).

Putnam, Hilary. 2004. The Collapse of the Fact/Value Dichotomy. Gambridge: Harvard University Press.

Shiner, Larry. 2001. The Invention of Art. A Cultural History. Chicago: The University of Chicago Press.

Wittgenstein, Ludwig. 1975. Philosophische Untersuchungen. Frankfurt am Main: Suhrkamp. 